\title{
Pengaruh cendawan endofit terhadap biologi dan statistik demografi wereng batang cokelat Nilaparvata lugens Stál (Hemiptera: Delphacidae)
}

\author{
Effects of endophytic fungi on the biology and the statistic \\ demographic of brown plant hopper Nilaparvata lugens Stál \\ (Hemiptera: Delphacidae)
}

\author{
Amanda Mawan, Damayanti Buchori*, Hermanu Triwidodo
}

Departemen Proteksi Tanaman, Fakultas Pertanian, Institut Pertanian Bogor Jalan Kamper, Kampus Darmaga IPB, Bogor 16680

(diterima Juni 2013, disetujui Juli 2013)

\begin{abstract}
ABSTRAK
Cendawan endofit merupakan mikroorganisme endosimbion yang hidup dalam jaringan tanaman inang tanpa menimbulkan gejala penyakit yang nyata. Kelompok cendawan ini penting sebagai mediator dalam interaksi tanaman-herbivora. Salah satu jenis cendawan endofit yang ada di tanaman padi adalah Nigrospora sp. Pengaruh Nigrospora sp. terhadap biologi dan statistik demografi wereng batang cokelat, Nilaparvata lugens Stál (Hemiptera: Delphacidae) diamati di laboratorium. Nigrospora sp. yang digunakan dalam penelitian merupakan cendawan endofit tanaman padi hasil biakan yang diformulasikan dalam bentuk tepung. Tepung endofit diinokulasikan pada benih padi dengan cara mencampurkan $10 \mathrm{~g}$ tepung endofit per $1 \mathrm{~kg}$ benih padi dan disimpan di tempat yang lembab dan gelap. Hasil penelitian menunjukkan bahwa padi yang diberi perlakuan cendawan endofit menunjukkan resistensi terhadap $N$. lugens. Peningkatan mortalitas telur dan nimfa instar awal lebih tinggi dibandingkan dengan perlakuan kontrol. Perlakuan cendawan endofit juga dapat memperpanjang lama perkembangan nimfa, periode praoviposisi, periode oviposisi serta tertundanya waktu peletakan telur oleh imago betina $N$. lugens. Cendawan endofit Nigrospora sp. memengaruhi pertumbuhan populasi $N$. lugens dalam skala laboratorium sehingga memiliki potensi sebagai pengendalian alternatif terhadap $N$. lugens. Selain itu, inokulasi cendawan endofit bisa menjadi metode yang berguna untuk melindungi tanaman padi dari $N$. lugens.
\end{abstract}

Kata kunci: usia saat pertama kali bereproduksi, fekunditas, mortalitas, Nigrospora sp., Nilaparvata lugens, pertahanan tanaman, sejarah kehidupan

\begin{abstract}
Endophytic fungi is an endosymbiont that lives within host plant tissues and does not necessary cause any harm to plants. This type of fungus are important as mediators in plant-herbivore interactions. One of the endophytic fungi in rice is Nigrospora sp. The effects of Nigrospora sp. on the biology and demographic statistic of Nilaparvata lugens Stál (Hemiptera: Delphacidae) were studied in the laboratory. We used Nigrospora sp. culture powder was used to inoculate the fungi to rice seeds by mixing $10 \mathrm{~g}$ of flour endophytic per $1 \mathrm{~kg}$ rice seeds. The mixture was then stored in damp and dark storage. Results showed that the rice seeds treated with endophytic fungi showed some resistance to $N$. lugens. Eggs and early stages of nymph mortality was increased, higher than the control. Endophytic fungi also affect the nymphs growth rates by slowing it down, prolonging
\end{abstract}

\footnotetext{
*Penulis korespondensi: Damayanti Buchori. Departemen Proteksi Tanaman, Fakultas Pertanian, Institut Pertanian Bogor,

Jalan Kamper, Kampus IPB Darmaga, Bogor 16680

Tel: +62251-8425980,Email: dami@indo.net.id,damibuchori@yahoo.com
} 
$N$. lugens life cycle, preoviposition period as well as delayed the age at first reproduction. $N$. lugens population growth is effected by Nigrospora sp. in laboratory scale. Thus, it has the potential as an alternative way to control $N$. lugens population. In addition, inoculation of endophytic fungi could be a useful method for protecting rice plants from $N$. lugens.

Key words: age at first reproduction, fecundity, mortality, Nigrospora sp., Nilaparvata lugens, plant defense, life history

\section{PENDAHULUAN}

Cendawan endofit merupakan mikroorganisme endosimbion yang mengkolonisasi jaringan tanaman tetapi tidak selalu menunjukkan gejala dan tidak menyebabkan kerusakan pada tanaman inang (Petrini 1992). Cendawan endofit mendapatkan nutrisi dan perlindungan dari tanaman inangnya sehingga dapat menghasilkan atau menginduksi tanaman untuk menghasilkan senyawa yang berperan dalam pertahanan tamanan terhadap hama, penyakit, dan tekanan lingkungan. Endofit berperan dalam meningkatkan kesehatan tanaman di lingkungan yang tidak kondusif (Clay \& Schardl 2002; Schulz et al. 2002). Cendawan endofit diketahui mampu mengubah karakteristik tanaman seperti ketahanan terhadap tekanan lingkungan, perubahan fisiologis, produksi fitohormon dan senyawa kimia lainnya (Azevedo et al. 2000).

Hingga saat ini, pada tanaman padi setidaknya terdapat 14 jenis cendawan endofit yang telah diidentifikasi, yaitu Fusarium, Aspergillus, Curvularia, Penicillium, Gilmaniella, Arthrobotrys foliicola (Zakaria et al. 2010), Nigrospora (Budiprakoso 2010), Acremonium, Pyrenochaeta, Cliocephalotrichum, Rhizopus, Trichotesium, dan Scopulariopsis (Istiadji 2011). Hasil penelitian Budiprakoso (2010) menunjukkan bahwa Nigrospora sp. menekan peluang hidup nimfa dan imago wereng batang cokelat (WBC). Hasil ini menunjukkan potensi cendawan endofit Nigrospora sp. sebagai salah satu faktor pembatas perkembangan populasi WBC.

Hasil eksplorasi lebih lanjut menunjukkan bahwa terdapat beberapa spesies cendawan endofit yang ditemukan pada tanaman ini salah satunya adalah Nigrospora sp. Berdasarkan hal tersebut dibutuhkan penelitian yang lebih mendalam untuk mengetahui pengaruh Nigrospora terdapat populasi WBC. Penelitian ini dilakukan sebagai salah satu usaha untuk mendapatkan informasi mengenai pengaruh cendawan endofit terhadap biologi dan 12 statistika demografi WBC. Pengaruh cendawan endofit terhadap kesintasan dan fekunditas WBC dapat diketahui dengan mengkonstruksi suatu neraca kehidupan (life table), dari neraca kehidupan akan didapatkan informasi rinci mengenai kelahiran, perkembangan, reproduksi, dan kematian setiap individu dalam suatu populasi. Informasi tersebut merupakan bahan dasar yang dibutuhkan untuk mempelajari berbagai aspek dan perilaku suatu populasi (Wilson \& Bossert 1971; Price 1997) yang berguna dalam merancang strategi alternatif untuk pengendalian WBC.

\section{BAHAN DAN METODE}

Penelitian dilaksanakan di Laboratorium Lapangan Departemen Proteksi Tanaman, Fakultas Pertanian, Institut Pertanian Bogor, Klaten, Jawa Tengah. Penelitian ini dilakukan bulan Februari sampai September 2012.

\section{Pemeliharaan Nilaparvata lugens}

Nilaparvata lugens Stál (Hemiptera: Delphacidae) (dipelihara pada tanaman padi varietas Ciherang berumur 1 sampai 1,5 bulan. Populasi awal WBC (nimfa dan imago) diperoleh dari pertanaman padi di Desa Serenan, Kecamatan Juwiring, Klaten, Jawa Tengah. Desa Serenan merupakan salah satu daerah endemik WBC di Kabupaten Klaten. WBC yang digunakan untuk memulai neraca kehidupan adalah imago betina WBC yang telah kawin dengan ciri-ciri, yaitu ukuran abdomennya yang besar. Pemeliharan WBC bertujuan untuk menjaga ketersediaan WBC sebagai serangga uji selama penelitian berlangsung.

\section{Aplikasi cendawan endofit pada tanaman padi}

Cendawan endofit yang digunakan dalam penelitian ini adalah Nigrospora sp.4. asal tanaman padi dan diformulasikan dalam bentuk tepung endofit yang diperoleh dari Klinik Tanaman 
Fakultas Pertanian, Institut Pertanian Bogor (IPB). Tepung endofit diaplikasikan pada benih padi sebelum penyemaian. Inokulasi cendawan endofit pada benih padi dilakukan untuk mengoptimalkan pertumbuhan jumlah koloni cendawan yang ada di dalam jaringan tanaman padi.

Cendawan endofit Nigrospora sp. merupakan anggota kelas Deuteromycetes, ordo Moniliales, famili Dematiaceae. Nigrospora sp. membentuk koloni yang pada awalnya berwarna putih kemudian secara perlahan berubah warna menjadi abu-abu dengan beberapa bagian berwarna hitam. Koloni Nigrospora sp. pada akhirnya akan menjadi hitam. Nigrospora sp. memiliki hifa septat dan hialin, konidiofornya hialin dengan sedikit pigmen. Konidia Nigrospora sp. berwarna hitam, uniseluler dan soliter.

Benih padi seberat $10 \mathrm{~g}$ direndam selama 24 jam. Benih yang tenggelam kemudian dimasukkan ke dalam cawan petri dan ditaburi tepung endofit. Berat tepung endofit dihitung berdasarkan rekomendasi Klinik Tanaman, yaitu $10 \mathrm{~g}$ tepung endofit per $1 \mathrm{~kg}$ benih padi. Cawan petri kemudian disimpan dalam keadaan gelap dan lembab untuk mempercepat proses perkecambahan.

Benih yang telah berkecambah disemai di baki berukuran $30 \mathrm{~cm} \times 21 \mathrm{~cm} \times 5 \mathrm{~cm}$ berisi tanah yang telah diberi pupuk dasar NPK sebanyak $2 \mathrm{~g}$. Media tanam yang digunakan terdiri atas tanah dan kompos dengan perbandingan $1: 1$. Bibit padi yang telah berumur 21 hari setelah semai (HSS) dapat digunakan untuk percobaan. Penyemaian dilakukan setiap hari sebagai stok tanaman uji dengan umur yang seragam.

\section{Pengaruh cendawan endofit terhadap Kohort} N. lugens

Kohort merupakan kelompok individu yang lahir dalam interval waktu yang hampir sama (Begon et al. 2006). Pengamatan pengaruh cendawan endofit terhadap kohort $N$. lugens dibagi menjadi dua perlakuan, yaitu tanaman padi tanpa inokulasi cendawan endofit dan tanaman padi yang diinokulasi cendawan endofit. Masing-masing perlakuan terdiri atas 20 ulangan. Pengamatan kohort WBC dilakukan dalam tiga tahap, yaitu

Pengaruh cendawan endofit terhadap lama stadia dan kesintasan telur $N$. lugens. Pengujian pengaruh cendawan endofit terhadap lama stadia dan kesintasan telur $N$. lugens dimulai dengan pemilihan 5 imago betina dengan abdomen besar yang dimasukkan ke dalam gelas plastik yang berisi 5 bibit padi berumur 21 HSS. Gelas plastik tersebut disungkup dengan kurungan mika berbentuk silinder $(\mathrm{d}=12 \mathrm{~cm}$ dan $\mathrm{t}=$ $30 \mathrm{~cm}$ ) dengan permukaan atas dan samping diberi ventilasi bertutupkan kain kasa. Betina WBC dikeluarkan dari kurungan setelah 24 jam. Pengamatan dilakukan setiap hari dengan mencatat jumlah nimfa instar I yang muncul dari setiap gelas. Pengamatan dilakukan selama 16 hari. Pada hari ke-17 tanaman kemudian dibedah di bawah mikroskop stereo untuk mengetahui jumlah telur yang tidak menetas.

Pengaruh cendawan endofit terhadap lama stadia dan kesintasan nimfa $N$. lugens. Lima nimfa instar I WBC yang muncul pada hari yang sama dimasukkan ke dalam gelas plastik yang berisi tanaman padi berumur 21 HSS. Jumlah nimfa yang hidup, mati, dan ganti kulit diamati dan dicatat perkembangannya setiap hari hingga menjadi imago. Jenis kelamin imago yang muncul juga dicatat.

Pengaruh cendawan endofit terhadap lama hidup imago $N$. lugens. Pengamatan lama hidup imago jantan dan betina dilakukan secara terpisah. Pengamatan imago jantan dimulai dengan memasukkan imago jantan yang baru muncul ke dalam tabung reaksi berisi 1 bibit padi berumur 21 HSS. Pengamatan dilakukan setiap hari hingga imago jantan terakhir mati.

Pengamatan untuk betina WBC dimulai dengan memasukkan 1 imago betina ke dalam tabung reaksi berisi 1 bibit padi berumur 21 HSS dan 2 imago jantan WBC. Imago jantan yang digunakan berasal dari hasil pemeliharaan. Setelah 24 jam ketiga imago tersebut dipindahkan ke dalam tabung reaksi baru berisi 1 bibit padi. Pemindahan tersebut dilakukan setiap hari hingga imago betina terakhir mati. Setiap tanaman yang telah terpapar WBC kemudian dibedah di bawah mikroskop stereo untuk menghitung jumlah telur yang diletakkan. Jumlah ulangan untuk masing-masing perlakuan tergantung pada jumlah imago yang muncul dari pengujian sebelumnya.

Lama stadia dianalisis dengan uji t menggunakan add in QIMacros 2013 untuk Microsoft Excel 2007. 
Uji t yang digunakan dalam menganalisis data ini adalah Two-Sample Assuming Equal Variances dan Two-Sample Assuming Unequal Variances $(\alpha=$ $0,05)$.

\section{Neraca kehidupan $N$. lugens}

Data hasil pengamatan Kohort WBC selama satu generasi disusun dalam bentuk neraca kehidupan. Neraca kehidupan Kohort merupakan neraca kehidupan yang mengikuti perkembangan Kohort dimulai dari kemunculan individu pertama (kelahiran) sampai kematian individu terakhir yang bertahan hidup (Begon et al. 2006). Dari data neraca kehidupan tersebut perhitungan dilanjutkan untuk menentukan parameter-parameter demografi lainnya (Birch 1948; Wilson \& Bossert 1971; Price 1997), seperti

1. Laju produksi kotor $(\mathrm{GRR})=\sum \mathrm{m}_{\mathrm{x}}$

2. Laju produksi bersih $\left(\mathrm{R}_{\mathrm{o}}\right)=\sum \mathrm{l}_{\mathrm{x}} \mathrm{m}_{\mathrm{x}}$

3. Laju pertumbuhan instrinsik $(r)=\frac{\ln R_{0}}{T}$

4. Rataan masa generasi $(T)=\sum X l_{x} m_{x} / \sum 1_{x} m_{x}$

5. Waktu berlipat ganda/doubling time $(\mathrm{DT})=$ $\ln (2) / \mathrm{T}$

6. Koreksi terhadap nilai $\mathrm{r}$ disesuaikan dengan persamaan Euler (Gotelli 1995), yaitu

Laju pertumbuhan $\left(\mathrm{r}_{\mathrm{m}}\right), \sum 1_{\mathrm{x}} \mathrm{m}_{\mathrm{x}} \mathrm{e}^{-\mathrm{mx}}=1$
Neraca kehidupan WBC disusun dengan menggunakan metode jack-knife untuk pendugaan ragam dari laju pertumbuhan intrinsik $\left(\mathrm{r}_{\mathrm{m}}\right)$. Metode jack-knife merupakan metode yang menggunakan teknik pengambilan ulang sampel (resampling) (Huang \& Chi 2012). Metode ini dilakukan dengan cara membuang data individu spesifik yang dipilih secara acak. Pengambilan ulang sampel dilakukan sebanyak 20 kali untuk masing-masing perlakuan.

\section{HASIL}

\section{Pengaruh cendawan endofit terhadap biologi N. lugens}

Formulasi cendawan endofit yang diinokulasikan ke tanaman padi memberikan pengaruh yang nyata terhadap beberapa parameter biologi WBC. Lama masa perkembangan nimfa instar I sampai V WBC menjadi lebih panjang pada populasi WBC yang dipelihara pada tanaman yang diberi perlakuan cendawan endofit dibandingkan dengan kontrol (Tabel 1). Walaupun lama stadia telur dan imago WBC tidak berbeda nyata untuk kedua perlakuan (cendawan endofit dan kontrol) akan tetapi, siklus hidup imago jantan dan betina WBC menjadi lebih panjang saat dipelihara pada tanaman yang diberi

Tabel 1. Selang dan rata-rata lama stadia Nilaparvata lugens tanaman padi kontrol dan tanaman padi yang diberi perlakuan cendawan endofit

\begin{tabular}{lrcrr}
\hline \multirow{2}{*}{ Stadia } & \multicolumn{2}{c}{ Selang (n) } & \multicolumn{2}{c}{ Rata-rata \pm galat* } \\
\cline { 2 - 5 } & \multicolumn{1}{c}{ Kontrol } & Cendawan endofit & \multicolumn{1}{c}{ Kontrol } & Cendawan endofit \\
\hline Telur & $7-17(301)$ & $7-17(135)$ & $12,19 \pm 0,11 \mathrm{a}$ & $11,89 \pm 0,18 \mathrm{a}$ \\
Instar I & $2-4(91)$ & $3-6(88)$ & $3,25 \pm 0,07 \mathrm{a}$ & $3,84 \pm 0,09 \mathrm{~b}$ \\
Instar II & $2-5(71)$ & $2-6(68)$ & $3,38 \pm 0,07 \mathrm{a}$ & $3,81 \pm 0,10 \mathrm{~b}$ \\
Instar III & $2-4(61)$ & $3-6(62)$ & $3,45 \pm 0,07 \mathrm{a}$ & $3,92 \pm 0,10 \mathrm{~b}$ \\
Instar IV & $2-4(55)$ & $3-5(58)$ & $3,45 \pm 0,07 \mathrm{a}$ & $3,91 \pm 0,10 \mathrm{~b}$ \\
Instar V & $3-5(55)$ & $3-6(57)$ & $3,65 \pm 0,08 \mathrm{a}$ & $3,95 \pm 0,10 \mathrm{~b}$ \\
Jantan & & & & \\
$\quad$ Siklus hidup & $36-48(23)$ & $39-51(26)$ & $43,83 \pm 0,68 \mathrm{a}$ & $46,58 \pm 0,53 \mathrm{~b}$ \\
$\quad$ Lama hidup & $11-19(23)$ & $8-9(26)$ & $16,13 \pm 0,51 \mathrm{a}$ & $16,00 \pm 0,52 \mathrm{a}$ \\
Betina & & & \\
$\quad$ Siklus hidup & $38-52(32)$ & $41-52(31)$ & $44,87 \pm 0,55 \mathrm{a}$ & $46,81 \pm 0,50 \mathrm{~b}$ \\
$\quad$ Lama hidup & $10-20(32)$ & $12-20(31)$ & $16,28 \pm 0,45 \mathrm{a}$ & $16,19 \pm 0,39 \mathrm{a}$ \\
$\quad$ Umur pertama & & & \\
$\quad$ meletakkan telur & $28-36(32)$ & $30-39(31)$ & $32,06 \pm 0,35 \mathrm{a}$ & $34,64 \pm 0,32 \mathrm{~b}$ \\
$\quad$ Periode praoviposisi & $3-4(32)$ & $3-5(31)$ & $3,47 \pm 0,09 \mathrm{a}$ & $4,03 \pm 0,16 \mathrm{~b}$ \\
$\quad$ Periode oviposisi & $7-17(32)$ & $7-17(31)$ & $12,81 \pm 0,44 \mathrm{a}$ & $12,16 \pm 0,43 \mathrm{~b}$ \\
$\quad$ Fekunditas & $20-90(32)$ & $20-81(31)$ & $51,97 \pm 3,25 \mathrm{a}$ & $49,35 \pm 2,77 \mathrm{a}$ \\
\hline
\end{tabular}

*angka pada baris yang sama yang diikuti huruf yang sama tidak berbeda nyata berdasarkan hasil uji t $(\alpha=0,05)$. 
perlakuan cendawan endofit. Kondisi tersebut merupakan pengaruh tidak langsung dari lama stadia nimfa yang semakin panjang.

Cendawan endofit juga menyebabkan periode praoviposisi menjadi lebih panjang yang secara tidak langsung mengakibatkan mundurnya waktu reproduksi dan memperpanjang periode oviposisi. Walaupun periode oviposisi WBC pada padi yang diberi perlakuan cendawan endofit lebih panjang tetapi fekunditas tidak berbeda nyata dengan fekunditas WBC pada padi kontrol.

\section{Pengaruh cendawan endofit terhadap neraca kehidupan $N$. lugens}

Cendawan endofit memengaruhi struktur populasi WBC. Hal ini ditunjukkan oleh meningkatnya jumlah telur yang tidak menetas pada bibit yang diberi perlakuan cendawan endofit (Gambar 1). Jumlah total telur yang menetas pada bibit yang diinokulasi cendawan endofit, yaitu $\pm 10 \%$ dari 1300 telur per 100 betina WBC. Hasil ini lebih rendah dibandingkan dengan kontrol, yaitu $\pm 19 \%$ dari 1506 telur per 100 betina WBC.
Semua nimfa WBC yang berhasil bertahan hidup melewati empat kali proses ganti kulit. Dari 100 telur WBC yang berhasil menetas, sebagai populasi awal, sekitar 32\% (kontrol) dan 31\% (cendawan endofit) berhasil menjadi imago betina. Laju kesintasan $\left(1_{x}\right)$ WBC untuk kedua perlakuan ditunjukkan pada Gambar 2. Kurva kesintasan WBC pada tanaman kontrol dan tanaman yang diberi perlakuan endofit memiliki pola yang hampir sama, yaitu rendahnya tingkat keberhasilan hidup selama proses perkembangan nimfa, terutama pada fase instar awal (instar I sampai III). Kedua perlakuan memiliki pola yang hampir sama. Namun, terdapat penurunan probabilitas keberhasilan hidup nimfa dan imago WBC ketika dipelihara pada tanaman yang diberi perlakuan cendawan endofit.

Kesintasan dan fekunditas WBC disusun berdasarkan data dari neraca kehidupan untuk setiap perlakuan (Gambar 3). Kurva tersebut menunjukkan penurunan kesintasan dan mundurnya waktu reproduksi WBC yang dipelihara pada tanaman yang diberi perlakuan cendawan endofit. Imago betina WBC meletakkan telur dalam jumlah sedikit pada

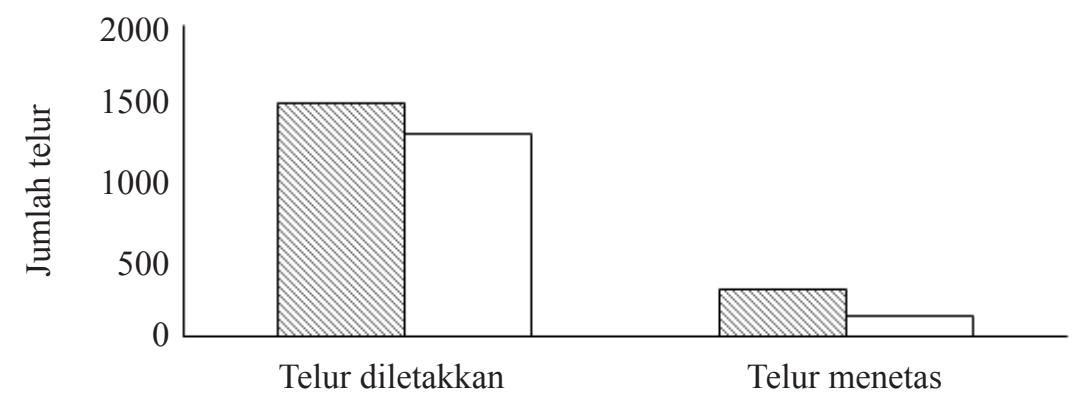

Gambar 1. Jumlah total telur Nilaparvata lugens yang diletakkan dan jumlah total telur yang menetas pada tanaman padi kontrol dan tanaman yang diberi perlakuan cendawan endofit. $\mathbb{k}$ :kontrol; $\square$ : cendawan endofit.

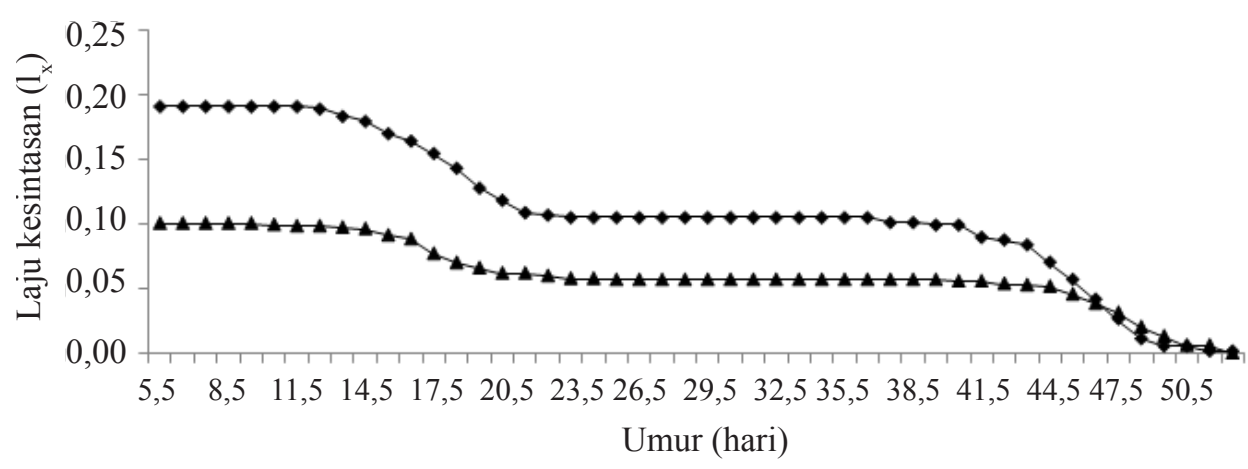

Gambar 2. Kurva kesintasan Nilaparvata lugens pada Kohort tanaman padi kontrol dan tanaman yang diberi perlakuan cendawan endofit. $\rightarrow-$ : kontrol; $\rightarrow$ : cendawan endofit. 
awal fase dewasa dan menjadi lebih banyak seiring pertambahan umur imago dan kembali menurun beberapa hari sebelum imago mati. Hal ini berlaku untuk kedua perlakuan.

Cendawan endofit memberikan pengaruh negatif dan positif terhadap parameter-parameter populasi WBC yang diamati (Tabel 2). Neraca kehidupan WBC menunjukkan bahwa pada populasi WBC yang dipelihara pada tanaman yang diberi perlakuan cendawan endofit generasi berikutnya akan meningkat sebanyak 28,06 kali dari generasi sebelumnya. Nilai $\mathrm{R}_{\mathrm{o}}$ tersebut lebih tinggi daripada tanaman kontrol (27,67 kali) akan tetapi, cendawan endofit berhasil memperlambat laju pertumbuhan intrinsik $\left(\mathrm{r}_{\mathrm{m}}\right)$, memperpanjang lama generasi $(\mathrm{T})$ dan waktu berlipat ganda (DT) WBC.

\section{PEMBAHASAN}

Cendawan endofit diketahui dapatmeningkatkan ketahanan tanaman melalui induksi pertahanan tanaman inangnya. Mekanisme induksi pertahanan tersebut berbeda untuk setiap strain cendawan dan tanaman inangnya (Selim et al. 2012). Secara umum, cendawan endofit menghasilkan senyawasenyawa metabolit sekunder yang memberikan pengaruh yang beragam terhadap hama dan penyakit (Schulz et al. 2002). Salah satu pengaruh yang dihasilkan oleh cendawan endofit terhadap serangga adalah perpanjangan lama stadia nimfa (pradewasa). Pada penelitian ini, cendawan endofit Nigrospora sp. diketahui memberikan pengaruh dalam perpanjangan lama stadia WBC. Pengaruh
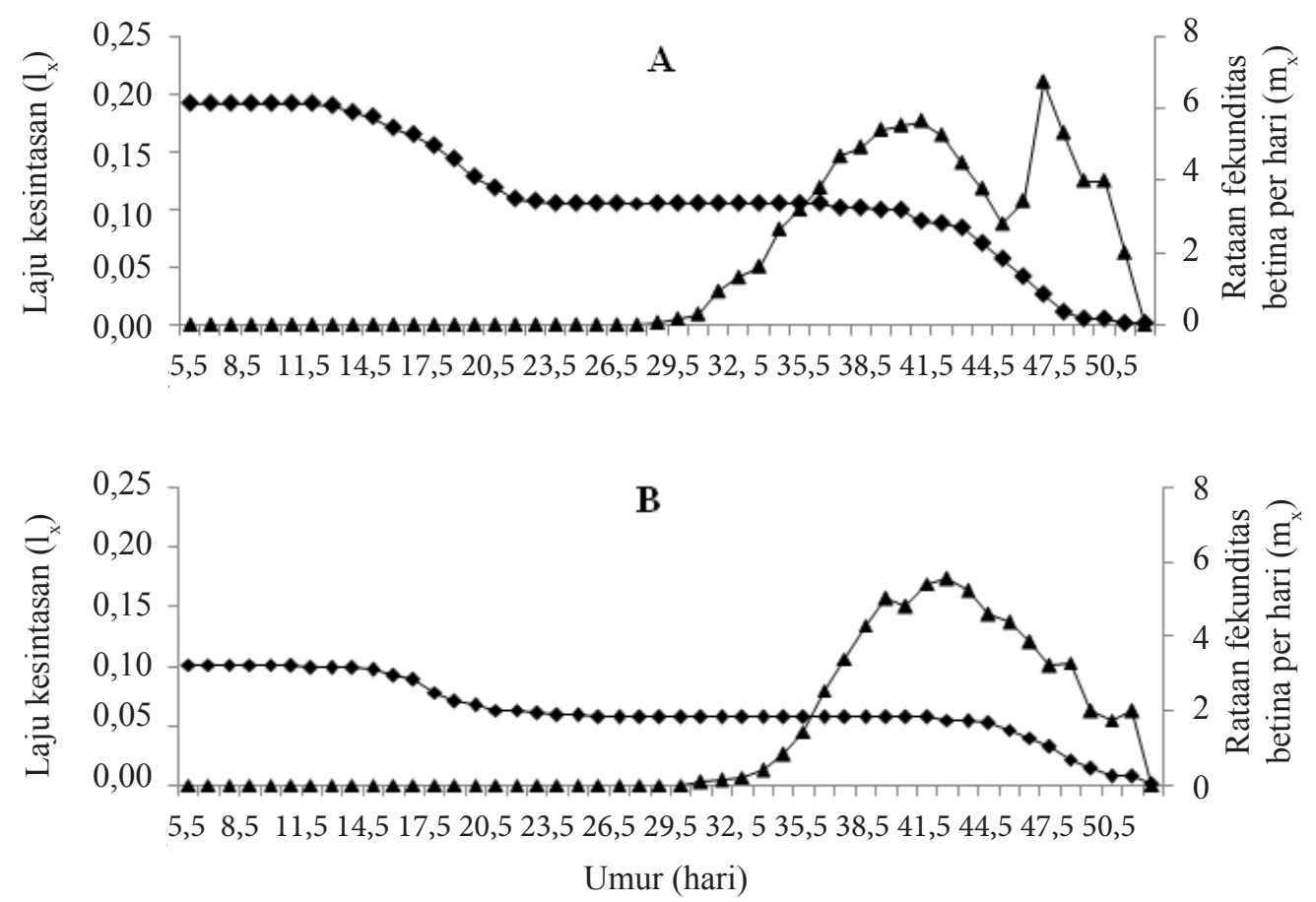

Gambar 3. Kesintasan dan fekunditas harian Nilaparvata lugens yang dipelihara pada tanaman padi kontrol (A) dan tanaman yang diberi perlakuan cendawan endofit (B). $\rightarrow-: 1_{\mathrm{x}}$ (laju kesintasan); $\multimap$ : $\mathrm{m}_{\mathrm{x}}$ (rataan fekunditas betina per hari).

Tabel 2. Statistik demografi Nilaparvata lugens \pm galat tanaman padi kontrol dan yang diberi perlakuan cendawan endofit

\begin{tabular}{lcc}
\hline \multirow{2}{*}{ Parameter } & \multicolumn{2}{c}{ Perlakuan } \\
\cline { 2 - 3 } & Kontrol* $^{*}$ & Cendawan endofit* \\
\hline Laju reproduksi kotor (GRR) & $82,26 \pm 0,05 \mathrm{a}$ & $64,28 \pm 0,05 \mathrm{~b}$ \\
Laju reproduksi bersih ( $\mathrm{R}_{\mathrm{o}}$ ) & $27,67 \pm 0,06 \mathrm{a}$ & $28,06 \pm 0,12 \mathrm{~b}$ \\
Laju pertumbuhan intrinsik $\left(\mathrm{r}_{\mathrm{m}}\right)$ & $0,085807 \pm 0,000057 \mathrm{a}$ & $0,081679 \pm 0,000089 \mathrm{~b}$ \\
Rataan lama generasi (T) (hari) & $38,700 \pm 0,005 \mathrm{a}$ & $40,821 \pm 0,016 \mathrm{~b}$ \\
Doubling time (DT) (hari) & $8,078 \pm 0,005 \mathrm{a}$ & $8,486 \pm 0,009 \mathrm{~b}$ \\
\hline *angka
\end{tabular}


yang serupa juga diberikan oleh Acremonium strictum yang menginfeksi tanaman tomat sehingga menyebabkan meningkatnya mortalitas larva dan memperpanjang waktu perkembangan larva Helicoverpa armigera (Hübner) (Jallow et al. 2004). Studi mengenai pengaruh cendawan endofit terhadap lama hidup serangga juga dilakukan Meister et al. (2005) yang mengamati lama hidup dua kutudaun Rhopalosiphum padi L. dan Metopolophium dirhodum (Walker) pada rerumputan yang diinokulasi cendawan endofit Neotyphodium lolii. Hasilnya menunjukkan bahwa endofit memperpendek lama hidup $R$. padi tetapi tidak memberikan pengaruh yang berarti terhadap lama hidup M. dirhodum. Dari hasil-hasil penelitian tersebut diketahui bahwa setiap serangga memberikan respons yang berbeda terhadap keberadaan cendawan endofit di dalam jaringan tanaman inang.

Penundaan waktu perkembangan nimfa memberikan pengaruh yang menguntungkan terhadap pengendalian hama. Imago betina memiliki beberapa parameter biologi tambahan, yaitu periode praoviposisi, periode oviposisi, umur pertama meletakkan telur (age at first reproduction [AFR]) dan fekunditas. Begon et al. (2006) menyatakan bahwa laju perkembangan yang cepat dapat meningkatkan kebugaran serangga dan mempercepat inisiasi reproduksi. Inisiasi reproduksi yang terjadi lebih awal dapat diartikan sebagai percepatan siklus hidup suatu generasi. Siklus hidup suatu generasi yang selesai dalam waktu singkat akan mengurangi kemungkinan hama terpapar terhadap serangan musuh alaminya. Kondisi ini akan menjadi pembatas dalam pemanfaatan musuh alami sebagai salah satu bentuk pengendalian hayati.

Periode praoviposisi dan umur betina saat meletakkan telur pertama kali merupakan karakteristik sejarah kehidupan (life history) suatu organisme yang dapat memengaruhi keberhasilan reproduksi dan kebugaran organisme tersebut (Stearns 1992). Secara tidak langsung kedua karakteristik tersebut akan memengaruhi proses reproduksi dan fekunditas organisme tersebut. Kozlowski (1992) juga menyatakan bahwa tertundanya waktu awal reproduksi akan berdampak terhadap peningkatan mortalitas sebelum reproduksi, penurunan masa reproduksi, penurunan output reproduksi dan waktu generasi menjadi lebih lama. Cendawan endofit menyebabkan perpanjangan periode praoviposisi yang mengakibatkan tertundanya proses peletakan telur pertama. Kondisi ini menyebabkan laju pertumbuhan populasi WBC menjadi lebih lambat dari kontrol. Akan tetapi, periode praoviposisi yang panjang tidak memengaruhi kebugaran WBC karena tidak ada perbedaan yang nyata dari fekunditas betina WBC yang dipelihara pada tanaman kontrol dengan tanaman yang diberi perlakuan cendawan endofit. Ada beberapa kemungkinan penyebab tidak berbedanya fekunditas WBC pada kedua perlakuan, salah satunya adalah jumlah koloni cendawan endofit yang terdapat di dalam jaringan padi. Hasil penelitian van Bael et al. (2009) menunjukkan bahwa jumlah koloni endofit memengaruhi efek yang ditimbulkannya terhadap hama. Jumlah koloni cendawan endofit Glomerella cingulata yang tinggi berpengaruh negatif terhadap kumbang daun Chelymorpha alternans Boheman yang menyerang Merremia umbellata di Panama.

Fekunditas yang hampir sama pada kedua perlakuan tidak berarti populasi telur tersebut memiliki laju kesintasan yang hampir sama. Laju kesintasan (survivorship rate) merupakan laju kematian organisme pada saat proses pertumbuhan suatu generasi berlangsung (Speight et al. 2008). Inokulasi cendawan endofit terhadap benih padi menyebabkan penurunan kesintasan telur WBC. Kondisi seperti ini juga dilaporkan pada taksa lain, bahwa penurunan kesintasan telur seringkali berhubungan dengan respons spesies terhadap tekanan lingkungan (Lienesch et al. 2000).

Fase perkembangan WBC yang merusak adalah pradewasa (nimfa) dan dewasa (imago) sehingga pengendalian pada fase telur lebih efektif karena belum menimbulkan kerusakan pada tanaman padi. Pola kesintasan nimfa dan imago WBC juga mengalami perubahan dengan menurunnya probabilitas keberhasilan hidup nimfa dan imago yang diduga karena keberadaan cendawan endofit. Pola kesintasan WBC untuk kedua perlakuan dapat digolongkan ke dalam kurva kesintasan tipe III. Gambar 2 hanya menunjukkan kesintasan nimfa dan imago WBC saja, sehingga pola khas kurva kesintasan tipe III tidak terlihat. Hal ini disebabkan oleh rendahnya kesintasan telur WBC. 
Pola kesintasan yang diamati menunjukkan bahwa pradewasa WBC lebih rentan terhadap gangguan dan kesesuaian kualitas makanan. Penggunaan tanaman padi yang mengandung cendawan endofit menimbulkan dugaan adanya efek penolakan dari nimfa dan imago WBC terhadap tanaman yang diberi perlakuan cendawan endofit tersebut. Efek penolakan tersebut dapat berupa penurunan nafsu makan yang berujung pada kematian individu.

Laju pertumbuhan intrinsik $\left(\mathrm{r}_{\mathrm{m}}\right)$ menggambarkan laju peningkatan populasi dengan sumber daya yang tidak terbatas (Price 1997). Pada penelitian ini menunjukkan bahwa pemberian cendawan endofit Nigrospora sp. dapat memperlambat laju pertumbuhan populasi WBC. Dengan kata lain, hasil penelitian ini memperkuat dugaan bahwa cendawan endofit Nigrospora sp. memiliki potensi untuk menekan laju pertumbuhan WBC.

Rataan lama generasi $(\mathrm{T})$ merupakan rata-rata waktu yang dibutuhkan sejak telur diletakkan sampai menjadi imago yang kemudian meletakkan telur untuk pertama kali (Price 1997; Begon et al. 2006). Wereng yang dipelihara pada tanaman yang diberi perlakuan cendawan endofit membutuhkan waktu perkembangan generasi yang lebih lama dibandingkan dengan tanaman kontrol. Menurut Southwood \& Henderson (2000), pertumbuhan populasi tergantung dengan lama generasi yang berkaitan dengan laju pertumbuhan. Semakin lama waktu yang dibutuhkan satu generasi untuk berkembang, maka semakin lambat pertumbuhan populasi tersebut. Laju pertumbuhan populasi WBC melambat akibat keberadaan cendawan endofit pada tanaman padi sehingga pada akhirnya dapat menyebabkan penurunan populasi WBC di laboratorium. Pertumbuhan yang lambat juga akan meningkatkan kemungkinan untuk menekan populasi WBC dengan menggunakan agen biokontrol lain seperti predator atau parasitoid.

Waktu berlipat ganda (DT), yaitu waktu yang dibutuhkan untuk suatu populasi menjadi berlipat ganda. Informasi mengenai $r_{m}$ dan DT berguna untuk menunjukkan pertumbuhan populasi pada kondisi lingkungan pertumbuhan yang konstan dan sumber daya yang tidak terbatas (Price 1997; Southwood \& Henderson 2000).
Dalam dinamika populasi suatu organisme, jumlah keturunan yang tinggi tidak menjamin akan terjadinya peningkatan laju pertumbuhan populasi organisme tersebut. Populasi WBC yang dipelihara pada tanaman yang diinokulasi cendawan endofit diketahui memiliki fekunditas yang tinggi tetapi tidak diikuti dengan laju kesintasan yang tinggi pula. Hal ini terlihat pada tingginya mortalitas pada fase telur WBC yang secara tidak langsung akan berdampak terhadap pertumbuhan populasi WBC.

Laju pertumbuhan populasi dipengaruhi secara langsung oleh lama generasi. Pada pengujian ini, cendawan endofit memperpanjang lama generasi WBC sehingga laju pertumbuhannya menjadi lebih lambat daripada kontrol. Pertumbuhan yang lambat akan meningkatkan kemungkinan untuk menekan populasi WBC dengan menggunakan agen biokontrol lain seperti predator atau parasitoid. Nilai DT WBC pada tanaman yang diberi perlakuan cendawan endofit membutuhkan waktu yang lebih lama untuk populasinya menjadi berlipat ganda dibandingkan dengan tanaman kontrol. Pemanfaatan cendawan endofit pada tanaman padi dapat memperlambat pertumbuhan populasi WBC.

\section{KESIMPULAN}

Inokulasi cendawan endofit Nigrospora sp. memberikan pengaruh negatif terhadap biologi WBC, yaitu memperpanjang lama stadia nimfa, siklus hidup jantan dan betina, periode praoviposisi, dan periode oviposisi, serta menunda umur betina saat meletakkan telur pertama kali, dan menyebabkan penurunan kesintasan telur WBC. Keberadaan cendawan endofit tidak memengaruhi lama hidup jantan dan betina serta fekunditas WBC. Cendawan endofit Nigrospora sp. dapat memperlambat pertumbuhan populasi WBC di laboratorium. Hal ini menunjukkan potensi pemanfaatan cendawan endofit sebagai agens pengendali hayati dalam mengendalikan WBC.

\section{DAFTAR PUSTAKA}

Azevedo JL, Macheroni W Jr, Pereira JO, Araújo WL. 2000. Endophytic microorganisms: a review on 
insect control and recent advances on tropical plants. Eletronic Journal of Biotechnology 3:01-36.

Begon M, Townsend CR, Harper JL. 2006. Ecology: From Individuals to Ecosystems. 4th edition. Oxford: Blackwell Publishing.

Birch LC. 1948. The intrinsic rate of natural increase of an insect population. Journal of Animal Ecology 17:15-26. doi: http://dx.doi. org/10.2307/1605.

Budiprakoso B. 2010. Pemanfaatan cendawan endofit sebagai penginduksi ketahanan tanaman padi terhadap wereng cokelat Nilaparvata lugens (Stál). (Hemiptera: Delphacidae). Skripsi. Bogor: Institut Pertanian Bogor.

Clay K, Schardl C. 2002. Evolutionary origins and ecological consequences of endophyte symbiosis with grasses. The American Naturalist 160:99127. doi: http://dx.doi.org/10.1086/342161.

GotelliNJ. 1995. A Primer of Ecology. Massachusets: Sinauer Associates.

Huang YB, Chi H. 2012. Assessing the application of the jackknife and bootstrap techniques to the estimation of the variability of the net reproductive rate and gross reproductive rate: a case study in Bactrocera cucurbitae (Coquillett) (Diptera: Tephritidae). Journal of Agriculture and Forestry 6:37-45.

Istiadji B. 2011. Analisis faktor kunci penyebab ledakan populasi hama wereng coklat Nilaparvata lugens Stal di Kabupaten Klaten. Tesis. Bogor: Institut Pertanian Bogor.

Jallow MFA, Dugassa-Gobena D, Vidal S. 2004. Indirect interaction between an unspecialized endophytic fungus and a polyphagous moth. Basic and Applied Ecology 5:183-191. doi: http://dx.doi.org/10.1078/1439-1791-00224.

Kozlowski J. 1992. Optimal allocation of resources to growth and reproduction: implications for age and size at maturity. Tree 7:15-19. doi: http:// dx.doi.org/10.1016/0169-5347(92)90192-E.

Lienesch L, Dumont J, Bantle J. 2000. The effect cadnium on oogenesis in Xenopus laevis. Chemosphere 41:1651-1658. doi: http://dx.doi. org/10.1016/S0045-6535(00)00046-1.
Meister B, Krauss J, Härri SA, Schneider V, Müller CB. 2006. Fungal endosymbionts affect aphid population size by reduction of adult life span and fecundity. Basic and Applied Ecology 7:244 252. doi: http://dx.doi.org/10.1016/j.baae.2005. 06.002 .

Petrini O. 1992. Fungal endhophytes of tree leaves. In: Andrews JH, Hirano SS (Eds), Microbial Ecology of Leaves. pp. 179-196. Berlin: Springer Verlag.

Price PW. 1997. Insect Ecology. $3^{\text {th }} \mathrm{ed}$. New York: John Wiley \& Sons.

Schulz B, Boyle C, Draeger S, Römmert AK, Krohn K. 2002. Endophytic fungi: a source od novel biologically active secondary metabolites. Mycological Research 106:996-1004. doi: http:// dx.doi.org/10.1017/S0953756202006342.

Selim KA, El-Beih AA, AbdEl-Rahman TM, ElDiwany AI. 2012. Biology of endophytic fungi. Current Research in Environmental \& Applied mycology 2:31-82. doi: http://dx.doi.org/10.5943 /cream $/ 2 / 1 / 3$.

Southwood TRE, Henderson PA. 2000. Ecological Methods. $3^{\text {th }} \mathrm{ed}$. Oxford: Blackwell Science.

Speight MR, Hunter MD, Watt AD. 2008. Ecology of Insect: Concepts and Application. $2^{\text {nd }}$ ed. Oxford: John Willey \& Sons.

Stearns SC. 1992. The evolution of life histories. Oxford: Oxford University Press.

van Bael SA, Valencia MC, Rojas EI, Gómez N, Windson DM, Herre EA. 2009. Effects of foliar endophytic fungi on the preference and performance of the leaf beetle Chelymorpha alternans in Panama. Biotropica 41:221-225. doi: http://dx.doi.org/10.1111/j.1744-7429.2008. 00476.x

Wilson EO, Bossert WH. 1971. AprimerofPopulation Biology. Sunderland: Sinauer Associates.

Zakaria L, Yaakop AS, Salleh B, Zakaria M. 2010. Endophytic fungi from paddy (Short communication). Tropical Life Sciences Research 21:101-107. 